\title{
Caracterização econômica dos municípios sul-mato-grossenses do Corredor Bioceânico
}

\author{
Economic characterization of the south-Mato Grosso municipalities of the \\ Bioceanic Highroad Crossing
}

\author{
Caracterización económica de los municipios sul-mato-grossenses de la Ruta \\ Bioceánica
}

\author{
Michel Constantino ${ }^{1}$ \\ Arlinda Cantero Dorsa ${ }^{1}$ \\ Daniel Silva Boson ${ }^{2}$ \\ Dany Rafael Fonseca Mendes²
}

Recebido em 13/08/2018; revisado e aprovado em 18/11/2018; aceito em 14/06/2019

DOI: http://dx.doi.org/10.20435/inter.v20iespecial.2119

\begin{abstract}
Resumo: A presente pesquisa teve por objetivo caracterizar, a partir de indicadores econômicos, os municípios de Mato Grosso do Sul (MS) com influência direta e indireta na criação do Corredor Bioceânico, que ligará o Brasil ao Oceano Pacífico. Para a presente análise, foram avaliados todos os municípios, em dois traçados distintos, entre a capital de Mato Grosso do Sul, Campo Grande e Porto Murtinho, cidade sul-mato-grossense que faz fronteira com Paraguai. Os indicadores econômicos utilizados foram: PIB; PIB per capita; população; arrecadação de impostos; valor adicionado bruto setorial; e atividade econômica principal, secundária e terciária. Os resultados trazem evidências não só de desenvolvimento econômico entre 2010 e 2015, como também de diferenças na variação do crescimento de acordo com a atividade produtiva de cada município avaliado. A análise de cluster apresentou municípios com similitudes, e, neste contexto, Campo Grande diverge dos demais municípios, enquanto Maracaju e Sidrolândia formam um cluster único de grande impacto econômico no Estado. Do ponto de vista econômico, Porto Murtinho - apesar do crescimento do setor de turismo no município - é a cidade mais vulnerável, apresentando baixa dinâmica produtiva, com uma economia baseada na pecuária e, ainda, fortemente dependente de recursos da administração pública.
\end{abstract}

Palavras-chave: fronteira; Mato Grosso do Sul; análise econômica; Corredor Bioceânico.

Abstract: The objective of this research was to characterize, based on economic indicators, the municipalities of Mato Grosso do Sul (MS) with direct and indirect influence on the creation of the Bioceanic Highroad Crossing, which will connect Brazil to the Pacific Ocean. For the present analysis, all the municipalities were evaluated, in two different routes, between the capital of Mato Grosso do Sul, Campo Grande and Porto Murtinho, south-mato-grossense city that borders Paraguay. The economic indicators used were: GDP; GDP per capita; the population; tax collection; gross sectoral value added; and main, secondary and tertiary economic activity. The results bring evidence not only of economic development between 2010 and 2015, but also of differences in the growth variation according to the productive activity of each municipality evaluated. The cluster analysis presented municipalities with similarities, and in this context, Campo Grande differs from the other municipalities, while Maracaju and Sidrolândia form a unique cluster of great economic impact in the State. From the economic point of view, Porto Murtinho- despite the growth of the tourism sector in the municipality- is the most vulnerable city, presenting low productive dynamics, with an economy based on livestock and, still, strongly dependent on administration resources public.

Keywords: border; Mato Grosso do Sul; economic analysis; Bioceanic Highroad Crossing.

Resumen: La presente investigación tuvo por objetivo caracterizar, a partir de indicadores económicos, los municipios de Mato Grosso do Sul (MS) con influencia directa e indirecta en la creación de la Ruta Bioceánica, que conectará el Brasil al Océano Pacífico. Para el presente análisis, se evaluaron todos los municipios, en dos trazados distintos, entre la capital de Mato Grosso do Sul, Campo Grande y Porto Murtinho, ciudad surmato-grossense que limita con Paraguay. Los indicadores económicos utilizados fueron: PIB; PIB per cápita; la población; recaudación de impuestos; valor agregado bruto sectorial; y la actividad económica principal, secundaria y terciaria. Los resultados traen evidencias no sólo de desarrollo económico entre 2010 y 2015 ,

\footnotetext{
${ }^{1}$ Universidade Católica Dom Bosco (UCDB), Campo Grande, Mato Grosso do Sul, Brasil.
}

${ }^{2}$ Centro Universitário de Brasília (UniCEUB),Campo Grande, Mato Grosso do Sul, Brasil. 
sino también de diferencias en la variación del crecimiento de acuerdo con la actividad productiva de cada municipio evaluado. El análisis de cluster presentó municipios con similitudes, y en este contexto, Campo Grande difiere de los demás municipios, mientras que Maracaju y Sidrolândia forman un cluster único de gran impacto económico en el Estado. Desde el punto de vista económico, Porto Murtinho - a pesar del crecimiento del sector turístico en el municipio - es la ciudad más vulnerable, presentando baja dinámica productiva, con una economía basada en la ganadería y, aún, fuertemente dependiente de recursos de la administración pública.

Palabras clave: frontera; Mato Grosso do Sul; análisis económico; Corredor Bioceánico.

\section{INTRODUÇÃO}

A partir da criação da Carta de Campo Grande e da Carta de Brasília, que resultaram na possibilidade de construção da ponte entre Brasil e Paraguai, o Corredor Bioceânico passou de uma aspiração de organizações privadas e públicas a uma realidade de infraestrutura, a qual, no futuro, permitirá a ligação entre Brasil e Chile, passando pelo Paraguai e a Argentina. Para este estudo, o Corredor foi traçado a partir de Campo Grande, por ser a capital do Mato Grosso do Sul e estar logisticamente localizada de forma estratégica no início do corredor de escoamento da produção agropecuária, sendo possível usar dois caminhos para se chegar à fronteira com o Paraguai, na cidade de Porto Murtinho.

Os municípios analisados foram Anastácio, Aquidauana, Bodoquena, Bonito, Campo Grande, Dois Irmãos do Buriti, Guia Lopes da Laguna, Jardim, Maracaju, Miranda, Nioaque, Porto Murtinho, Sidrolândia e Terenos. Contemplam estes municípios os dois caminhos possíveis entre Campo Grande e Porto Murtinho e, com a criação do Corredor Bioceânico, eles serão atingidos por influências diretas e indiretas, especialmente com relação à economia. O procedimento de pesquisa foi exploratório, com abordagem quantitativa, e a análise foi realizada com dados oficiais do Instituto Brasileiro de Geografia e Estatística (IBGE). O período de análise vai de 2010 a 2015, e as variáveis utilizadas foram o Produto Interno Bruto PIB per capita, a população, a arrecadação de impostos, o valor adicionado bruto setorial e a atividade econômica principal, secundária e terciária.

O objetivo da presente pesquisa foi caracterizar economicamente os municípios do Mato Grosso do Sul que, desde o início das obras para a criação do Corredor Bioceânico, possam sofrer influências diretas e indiretas e, a partir uma análise quantitativa, demonstrar as suas diferenças, as suas similaridades, a dependência produtiva e as vulnerabilidades econômicas.

Para o alcance do objetivo proposto, o estudo foi dividido nesta introdução (seção 1), em um breve contexto do desenvolvimento econômico no Mato Grosso do Sul (seção 2), nas análises municipais (seção 3), na análise de Cluster (seção 4) e correlação das variáveis (seção 5), na avaliação de exportações (seção 6) e, conclusivamente, na caracterização de uma situação de vulnerabilidade especial, perceptível em Porto Murtinho.

\section{DESENVOLVIMENTO ECONÔMICO DE MATO GROSSO DO SUL}

O setor econômico do Mato Grosso do Sul é dinâmico e passou por uma reorganização produtiva desde a criação do Estado, em 1977, inserindo-se num processo de modernização continua e ativa, aumentando a sua competitividade e o consolidando uma estrutura produtiva de referência. Contando com um território de 357.139,9 km², área correspondente a $18 \%$ da região Centro-Oeste e 4,19\% do Brasil, Mato Grosso do Sul possui uma localização privilegiada, 
tanto pela sua proximidade dos centros urbanos quanto pela extensa região fronteiriça com o Paraguai e a Bolívia, situação esta que Ihe confere grandes possibilidades de comércio com estes países (BRASIL, 2006).

Após a divisão do Estado de Mato Grosso e a respectiva criação de Mato Grosso do Sul, o Estado passou a experimentar um crescimento elevado, especialmente com relação à mecanização da agricultura e a modernização da pecuária e, consequentemente, com a implementação da agroindústria. Em 2014, o Produto Interno Bruto do Estado foi de R\$ 78,9 bilhões, representando $1,2 \%$ da participação no PIB nacional, com crescimento real acumulado de $530 \%$ no período de 2000 a 2014 (IBGE, 2017).

A proximidade em relação aos grandes centros consumidores de São Paulo e Paraná potencializou o desenvolvimento de cidades, como Três Lagoas, atualmente maior produtora de celulose do mundo, e a fronteira com Paraguai e Bolívia tem reativado o escoamento da produção por ferrovia e pelo Rio Paraguai. Atualmente, mais de $50 \%$ da produção agropecuária do Mato Grosso do Sul é exportada para a Ásia, principalmente para a China. Após a criação do Corredor Bioceânico, as condições que contribuem favoravelmente para um cenário de redução de custos, diminuição dos gargalos nacionais e prosperidade da economia a partir da parceria entre os países do Corredor, poderão potencializar oportunidades em investimentos, renda e emprego.

Apropriando-se das inovações tecnológicas lançadas especialmente pelo setor agrícola, Mato Grosso do Sul se destacou nacionalmente ao apresentar resultados expressivos na agropecuária. De acordo com o IBGE (2017), a participação da atividade primária (agropecuária) no PIB sul-mato-grossense foi de 15,45\% em 2014. Neste panorama, considerando o comércio exterior, o Estado contribuiu com 1,51\% do total das exportações do Brasil, ou seja, US\$ 5,2 bilhões (BRASIL, 2017). Relativamente às importações, a participação do Mato Grosso do Sul, ainda de acordo com dados do Ministério da Indústria, Comércio Exterior e Serviços (2017), foi de 1,81\%, representando aproximadamente US\$ 5,7 bilhões.

\section{CARACTERIZAÇÃO ECONÔMICA DOS MUNICÍPIOS DO CORREDOR BIOCEÂNICO}

Com objetivo de investigar o desempenho econômico dos municípios do Corredor Bioceânico no Mato Grosso do Sul, este estudo se baseou em dados do IBGE entre 2010 e 2015, abordando as principais variáveis utilizadas como proxy para desenvolvimento econômico. Uma análise exploratória dos dados foi realizada para compreender as características municipais e a abordagem de correlação propiciou o cômputo das relações mais importantes entre as variáveis.

\subsection{Produto Interno Bruto dos Municípios}

Uma das variáveis mais utilizadas na literatura para medir o desenvolvimento econômico é o Produto Interno Bruto (PIB). Este mede a riqueza agregada produzida pelo município a partir da soma do consumo $(C)$, do investimento $(I)$, dos gastos públicos $(G)$ e das exportações líquidas (EL), calculado pela equação $\mathrm{PIB}=\mathrm{C}+\mathrm{I}+\mathrm{G}+\mathrm{EL}$ (utilizado como proxy de prosperidade econômica entre os municípios analisados).

Entre 2010 e 2015, os municípios do Mato Grosso do Sul apresentaram Produto Interno Bruto, com variações similares e média de $70 \%$ de variação positiva, sem registro de diminuição de riquezas dos municípios avaliados para o período selecionado. Dois Irmãos do Buriti teve o maior crescimento percentual do PIB, com variação positiva de $217,44 \%$, descolando-se dos 
demais municípios e apresentando uma dinâmica econômica maior, em função de ter sua atividade principal voltada para a economia florestal. No mesmo período de análise, o município de Bonito, com economia baseada em serviços, apresentou aumento de 104,22\% do Produto Interno Bruto (IBGE, 2017).

O município de Campo Grande tem a economia baseada em serviços e, no quinquênio avaliado, isto é, de 2010 a 2015, seu PIB cresceu aproximadamente 60,76\%, conforme dados do IBGE (2017), apresentados em bilhões de reais na Figura 1. Embora Campo Grande seja um dos municípios responsáveis pelo crescimento do Estado, Anastácio, Guia Lopes, Terenos, Maracaju, Sidrolândia e Bonito se destacam com acréscimo superior a $70 \%$ na sua economia no mesmo período de análise. O município de Porto Murtinho, que vai receber a ponte sobre o Rio Paraguai, ligando o Brasil ao Paraguai, apresentou a menor variação do PIB entre os municípios, crescendo somente 26,72\% no mesmo quinquênio (IBGE, 2017).

Figura 1 - PIB dos Municípios do MS (em bilhões - R\$)

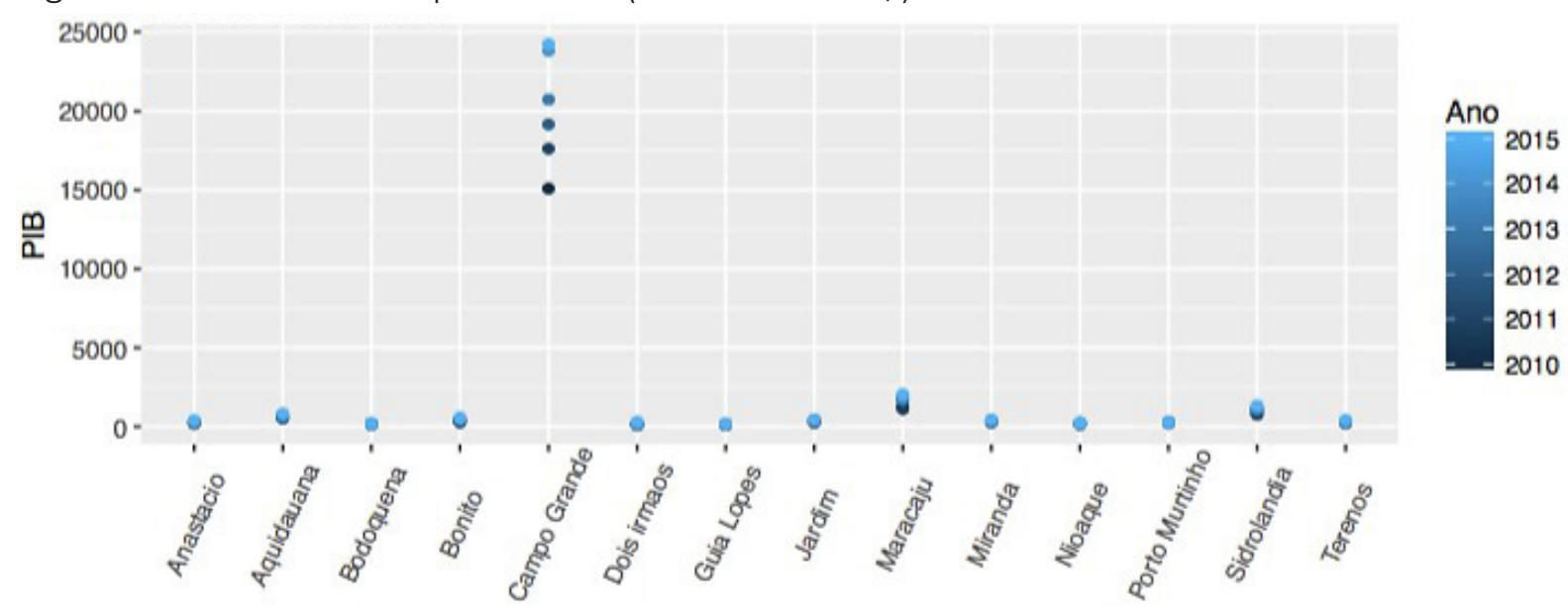

Fonte: IBGE (2017).

A Figura 1 apresenta o valor do PIB dos municípios e sua variação entre 2010 e 2015. Neste contexto, Campo Grande apresenta o maior resultado, e os demais municípios demonstram comportamento similar, destacando-se Maracaju e Sidrolândia, que aumentaram suas riquezas a partir do agronegócio e, no quinquênio, diferenciaram-se dos demais municípios analisados. Os resultados do PIB demonstram que os municípios têm suas economias lastreadas em diferentes dinâmicas produtivas, sendo importante entender essas dinâmicas para dar prioridade a externalidades positivas do Corredor Bioceânico para os municípios de menor crescimento, sem, contudo, deixar de potencializar aqueles que apresentam maior crescimento econômico.

\subsection{Produto Interno Bruto per Capita dos Municípios}

A renda média da população municipal é medida pela razão entre o PIB e a população de cada município, sendo um indicador de bem-estar que denota a capacidade de renda de cada habitante, ou seja, quanto maior o índice, maior o indício de bem-estar da população. A evolução do PIB per capita pode ser utilizada para comparações entre municípios, regiões, Estados e países. Logo, e quanto maior, maior o bem-estar. O PIB per capita é utilizado na literatura específica, em pesquisas e análises, com olhar dirigido a diferentes perspectivas e, neste estudo, a verificação 
estará focada em como a renda média da população pode se tornar fonte de desenvolvimento para o município. Entre 2010 e 2015, os municípios analisados apresentaram aumento significativo na renda per capita, o que pode denotar maior bem-estar da população.

Utilizando os dados do IBGE (2017) na análise, destaca-se Porto Murtinho que receberá a ponte entre Brasil e Paraguai, pois é o município com a menor variação percentual $(\Delta \%)$ do PIB per capita das cidades avaliadas, crescendo somente 17,89\% entre 2010 e 2015. Quando comparado aos demais municípios, no mesmo quinquênio, o crescimento do índice de Porto Murtinho é relativamente pequeno, pois os dados do IBGE (2017) permitem verificar municípios em análise aumentaram exponencialmente sua renda per capita, entre os quais Dois Irmãos do Buriti, com uma variação percentual de 200,11\%, Bonito, com aumento de 90,17\%, Anastácio, com $\%$ de 86,10\%, Guia Lopes, com $80,47 \%$ de majoração, e Jardim, com $66,76 \%$ de $\%$. O PIB per capita é apresentado, em valores, na Figura 2, e esse aumento é representado na mudança entre os anos de 2010 a 2015.

O município de Maracaju tem o maior PIB per capita em valores (mil reais) entre os municípios analisados, seguido de Campo Grande, Sidrolândia, Dois Irmãos do Buriti e Bonito. Analisando a variação do Produto Interno Bruto per capita, Dois Irmãos do Buriti apresentou a maior variação percentual, enquanto que Bonito e Anastácio completam, respectivamente, as maiores variações, conforme Figura 2. Porto Murtinho possui a menor variação do PIB per capita, e é uma das menores rendas médias entre os municípios analisados.

Figura 2 - PIB per Capita dos Municípios (em mil - R\$)

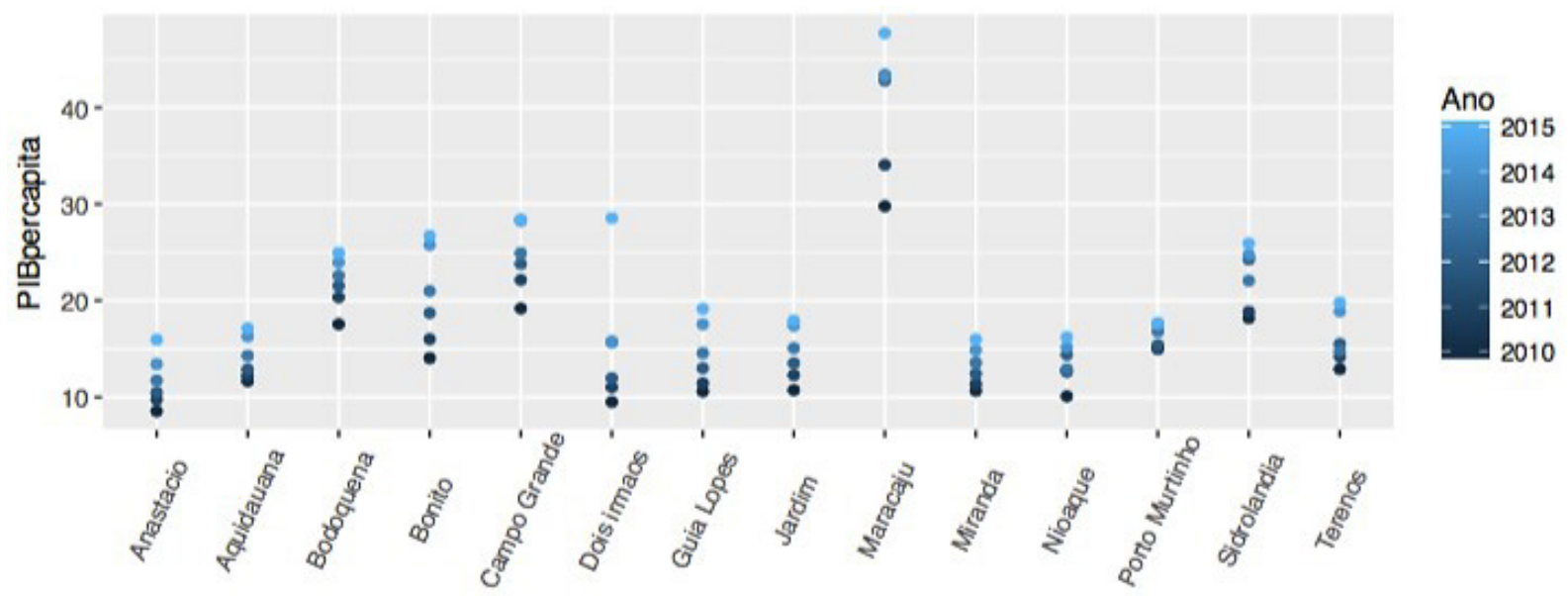

Fonte: IBGE (2017).

A riqueza média da população de Mato Grosso do Sul é, em geral, maior que a média nacional, permitindo colocar o Estado em uma posição significativa do ranking de desenvolvimento econômico. É, portanto, fundamental analisar cada município e sua dinâmica, entender o crescimento a partir das origens, investimentos realizados e participação das iniciativas locais do processo de construção do desenvolvimento.

\subsection{População dos Municípios e Arrecadação de Impostos}

A população de Mato Grosso do Sul era de 2.713.147 habitantes, segundo estimativa publicada pelo IBGE em 2017. O número é pouco maior que o estimado em agosto do ano anterior 
(2.682.386 moradores), demonstrando, assim, uma das características do Estado que é a baixa variação de crescimento populacional. Os dados dos municípios que compõem o Corredor Bioceânico, dentro do Mato Grosso do Sul, não são diferentes, sendo Campo Grande o único município que se destaca em termos de densidade populacional, enquanto que os demais apresentam baixa variação percentual de crescimento populacional entre 2010 e 2015.

Figura 3 - População dos Municípios (em mil)

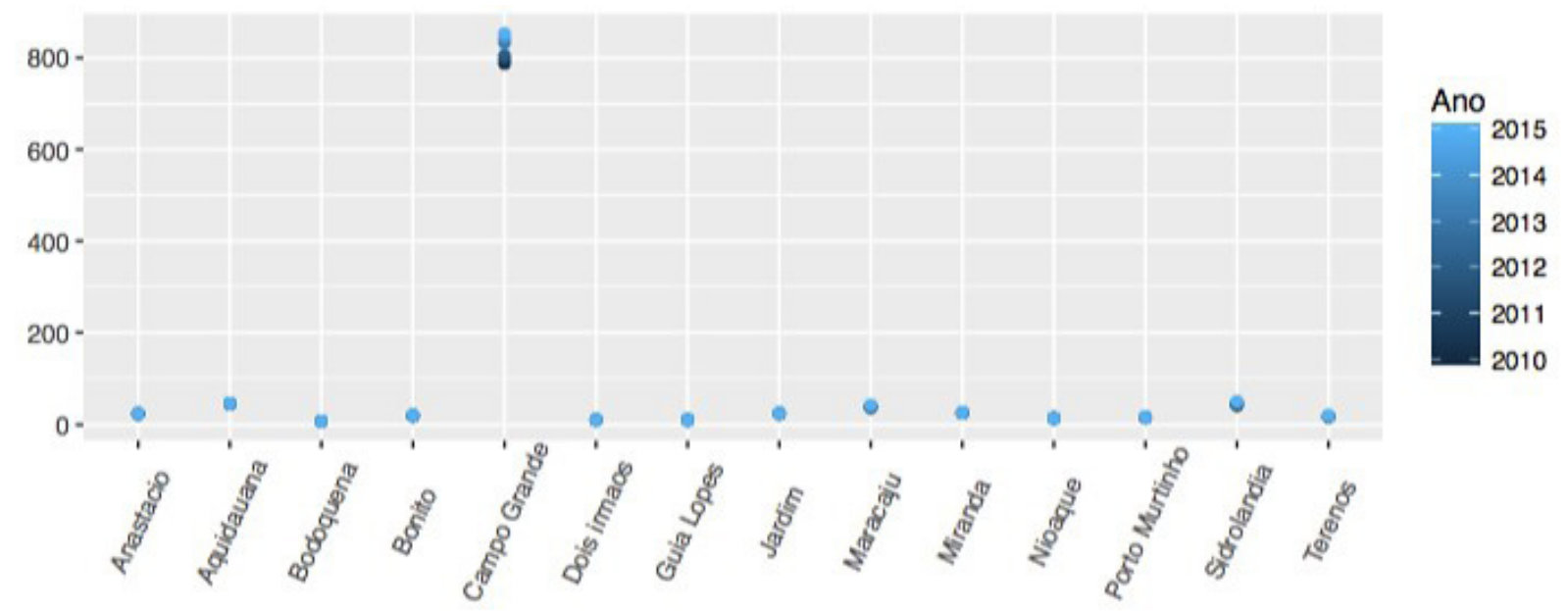

Fonte: IBGE (2017).

A Figura 3 destaca que a densidade populacional (quantidade em mil) dos municípios é baixa e homogênea, exceto para Campo Grande. Essas são características de municípios com grandes extensões de áreas agropecuárias, com baixa densidade demográfica e, ainda, com alta renda per capita relacionada à cadeia do agronegócio.

Além da quantidade populacional dos municípios, outra variável que caracteriza economicamente os prováveis participantes do Corredor Bioceânico é a arrecadação de impostos dos municípios. A arrecadação é um indicador econômico, produtivo e social, dado que os valores arrecadados são destinados para o bem público, e evidências empíricas, como em Constantino et al (2016) e Pegorare et al (2018) ao afirmarem que o aumento da arrecadação pode trazer melhorias na qualidade de vida das pessoas e no desenvolvimento dos municípios.

Os dados do IBGE (2017) são apresentados na Figura 4 em valores (milhões de reais), caracterizando os municípios que, entre os analisados, mais tiveram variação na arrecadação de impostos entre 2010 e 2015. A maior variação percentual de arrecadação foi em Campo Grande, seguida de Maracaju, Sidrolândia, Bonito e Aquidauana. Apesar da baixa variabilidade, todos os municípios apresentaram variação positiva e as atividades produtivas contribuíram para o crescimento da arrecadação de impostos. 
Figura 4 - Impostos Arrecadados dos Municípios (em milhões - R\$)

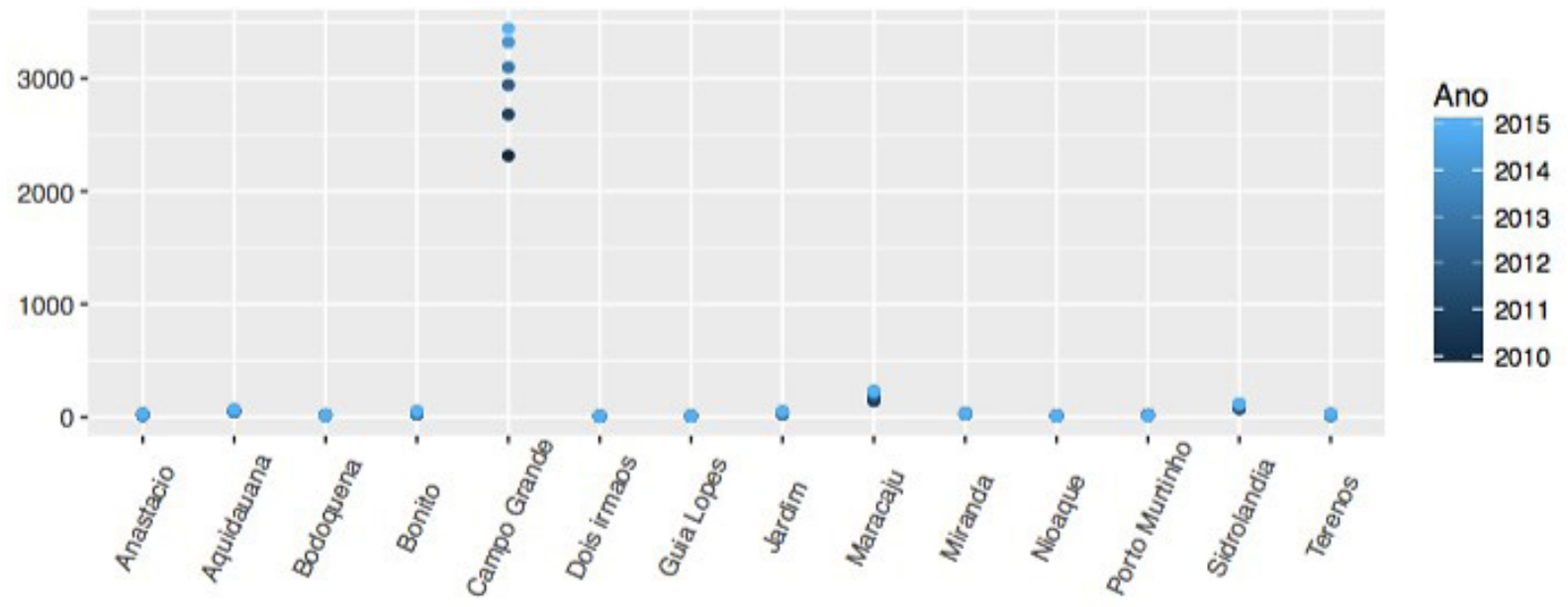

Fonte: IBGE (2017).

O município de Maracaju tem a maior empresa em receita total de Mato Grosso do Sul. Trata-se de uma cooperativa que tem efeito multiplicador no crescimento econômico do agronegócio nacional e, por essa razão, o município apresenta variação positiva na arrecadação de impostos. O Produto Interno Bruto, a renda per capita e a arrecadação de impostos fazem parte do fluxo circular da renda (MANKIW, 2004), que, na literatura econômica, é atribuído à riqueza gerada pelos municípios, estados e países. A análise desse fluxo permite compreender uma parte da dinâmica do desenvolvimento econômico, incluindo as potencialidades e as vulnerabilidade dos municípios analisados.

\subsection{Valor Adicionado Bruto - Setorial}

Além do Produto Interno Bruto, o IBGE calcula o Valor Adicionado Bruto (VAB) de cada setor econômico, o VAB dos principais setores econômicos dos municípios permite entender a atividade principal de cada município e sua composição na dinâmica produtiva. No Mato Grosso do Sul, a característica agroindustrial é confirmada nos estudos de Constantino, Pegorare e Costa (2016) e Pegorare et al (2018), sendo o principal meio produtivo, principalmente dos pequenos municípios.

A economia de Mato Grosso do Sul está dividida em quatro setores principais, isto é, Agronegócio, Indústria, Serviços e Administração Pública. Esses setores são responsáveis pelo VAB das atividades produtivas de cada município e é possível avaliar o impacto de cada setor na economia do Estado. 


\subsubsection{VAB do Agronegócio}

Figura 5 - VAB do Agronegócio dos Municípios (em bilhões - R\$)

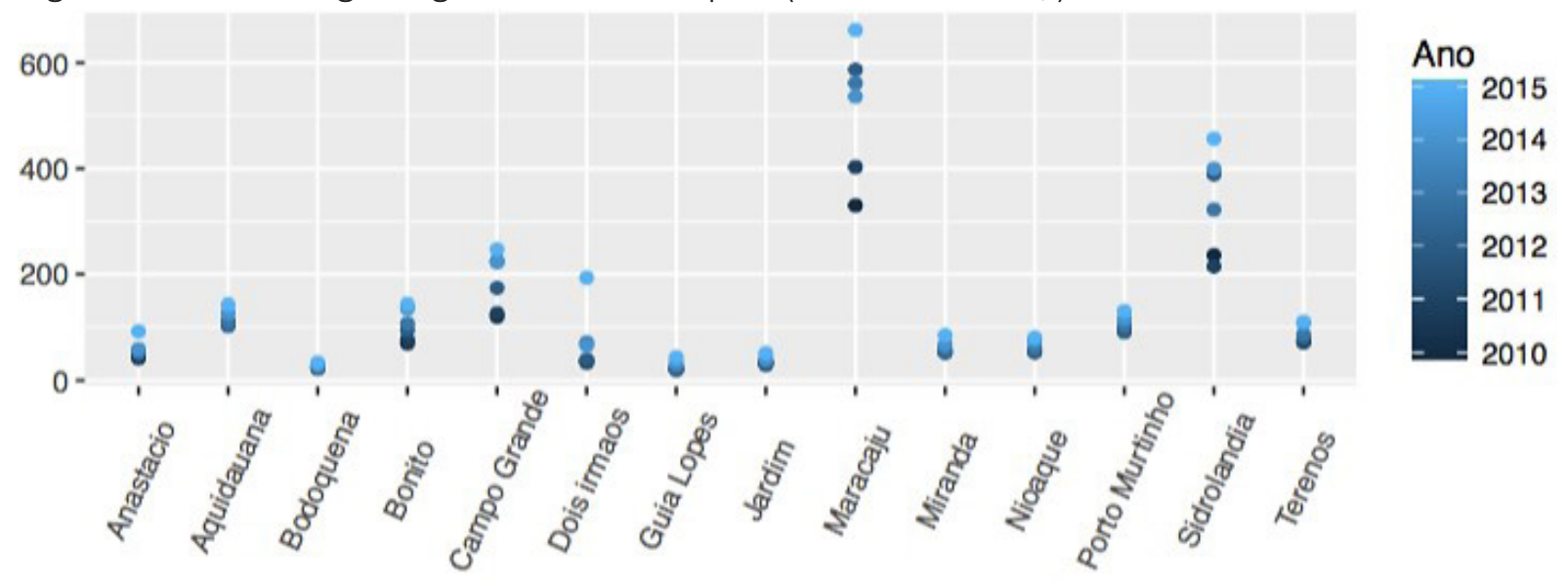

Fonte: IBGE (2017).

O VAB do agronegócio apresentou a maior variação positiva no município de Maracaju, conforme a Figura 5. No mesmo período, entre 2010 e 2015, outro município que apresentou aumento marginal crescente e exponencial foi Sidrolândia, que, além da criação de gado de corte, tem como atividade principal as lavouras de soja e milho. De acordo com os dados da Figura 5, todos os demais municípios tiveram efeitos positivos no VAB do agronegócio entre 2010 e 2015, uma dinâmica inerente ao Estado, que é produtor e exportador de commodities.

\subsubsection{VAB da Indústria}

Figura 6 - VAB da Indústria dos Municípios (em bilhões R\$)

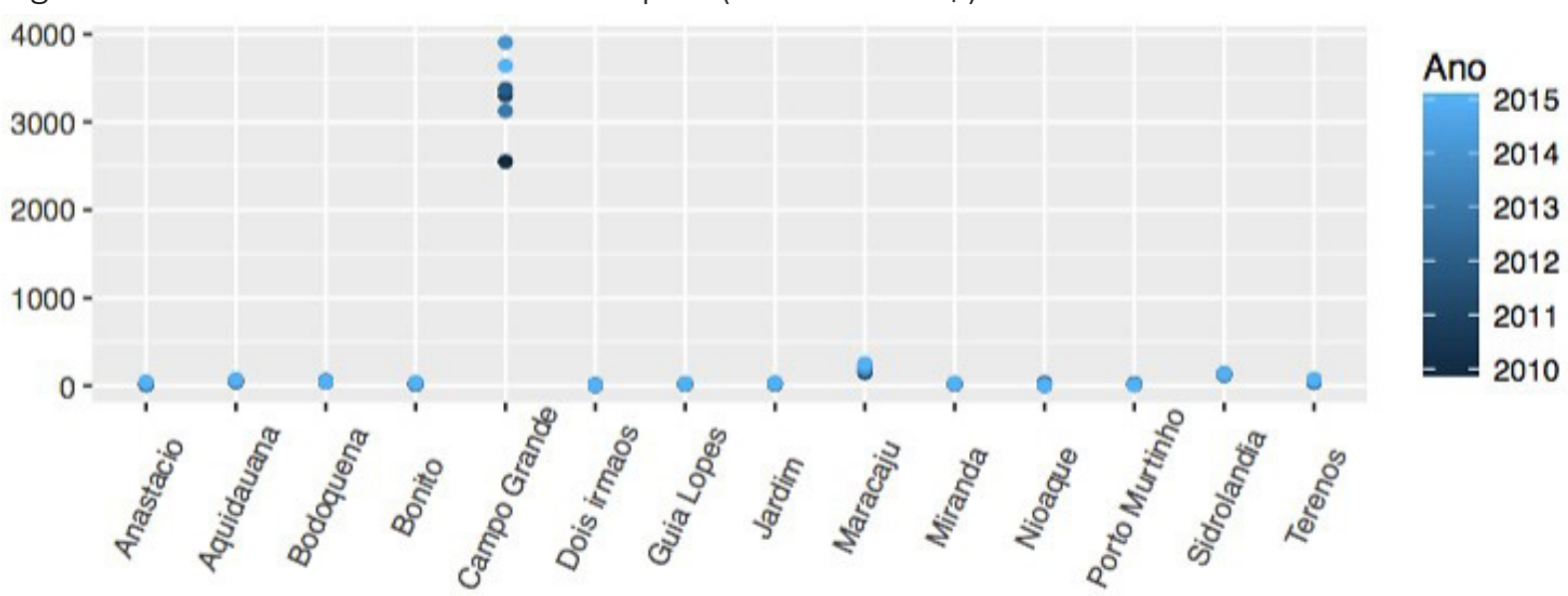

Fonte: IBGE (2017).

A indústria do Mato Grosso do Sul cresceu entre 2017 e 2018, de acordo com dados estimados pelo IBGE (2017), e, em 2017, o PIB Industrial atingiu R\$18,3 bilhões, com previsão de chegar a R\$19,4 bilhões em 2018, enquanto que para 2019 o montante previsto é de $\mathrm{R} \$$ 20,8 bilhões. O município que, em termos de atividade industrial, mais se destaca em crescimento é Três Lagoas, na divisa com o Estado de São Paulo, e, atualmente, comporta a maior planta de produção de papel e celulose do mundo. Considerando apenas os municípios que compõem o 
Corredor Bioceânico no Mato Grosso do Sul, Campo Grande se destaca, enquanto que Maracaju apresenta aumento significativo entre 2010 e 2015, conforme Figura 6.

\subsubsection{VAB dos Serviços}

Figura 7 - VAB dos Serviços dos Municípios (em bilhões R\$)

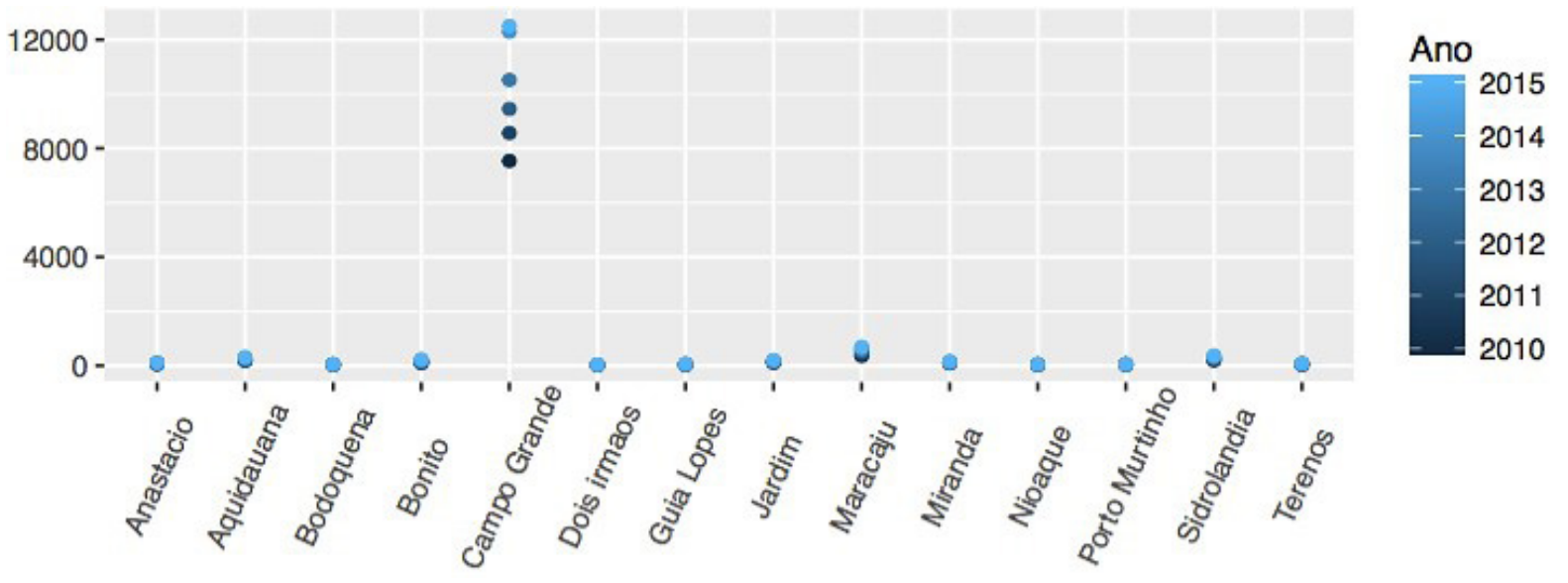

Fonte: IBGE (2017).

Campo Grande se tornou o centro financeiro do Mato Grosso do Sul. É onde se encontram instaladas as sedes das maiores organizações empresariais, sejam estas de serviços financeiros (bancos), telefonia, segurança, transporte, armazenagem e educação etc. Nesse panorama, Campo Grande apresenta o maior VAB de serviços e também, entre outros, a maior variação percentual positiva, seguida de Maracaju, que oferece os serviços de armazenagem de grãos, e de Bonito, atrelada aos serviços de turismo, conforme Figura 7.

\subsubsection{VAB da Administração Pública}

Figura 8 - VBA Administração Pública dos Municípios (em Bilhões - R\$)

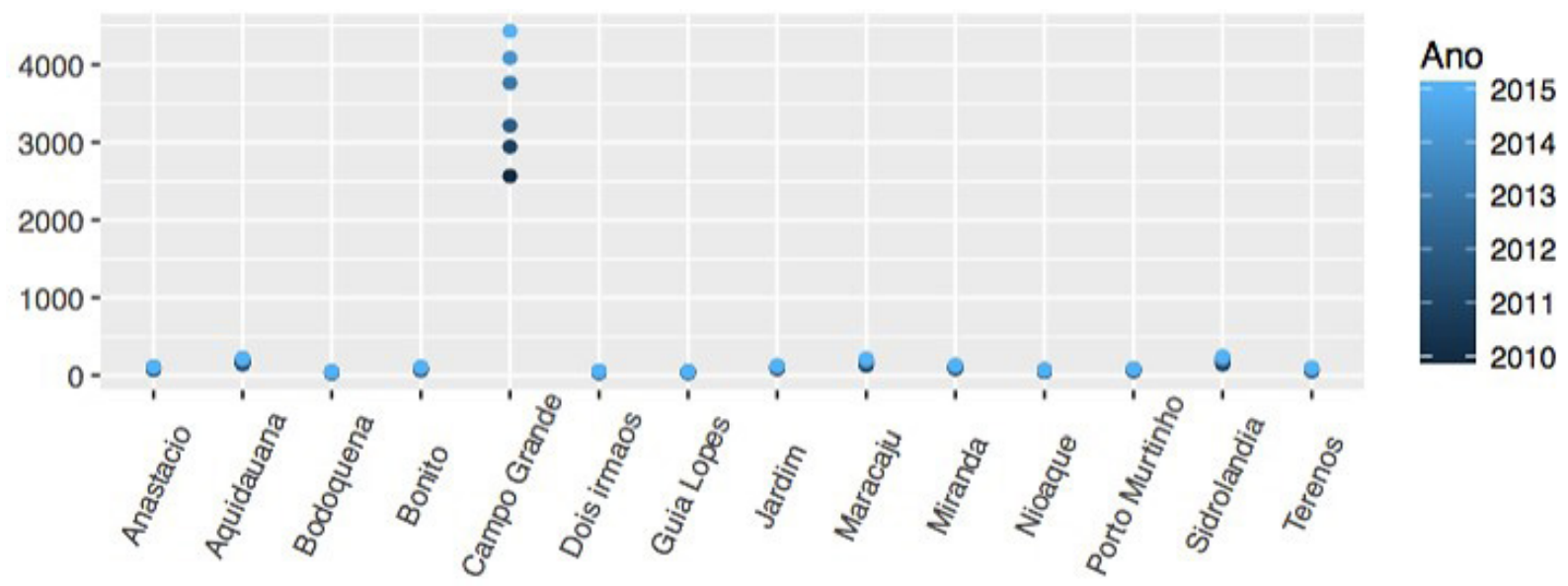

Fonte: IBGE (2017).

O VAB da Administração Pública analisa a importância da atividade administração, saúde e educação públicas e seguridade social na economia municipal, que, no Brasil, é caracterizada pela elevada participação no valor adicionado bruto de grande parte dos municípios (IBGE, 2017). 
Para os municípios analisados, os resultados mostram variação positiva e significativa para Campo Grande, Aquidauana, Bonito, Maracaju, Sidrolândia e Terenos, conforme Figura 8. Entre 2010 e 2015, Campo Grande, Maracaju, Sidrolândia, Dois Irmãos do Buriti e Bonito tiveram resultados significativos e, analisando o VAB total, estes municípios têm suas economias baseadas em agricultura, isto é, Maracaju e Sidrolândia, produção florestal, ou seja, Dois Irmãos do Buriti, e serviços, isto é, Bonito e a capital, Campo Grande. Em regra, os municípios que tiveram baixa variação da renda média e do VBA total têm sua economia voltada para o setor público.

Para conhecer as atividades produtivas principais de cada município, o IBGE disponibiliza os dados das três atividades que mais geram receita direta para eles, desde a atividade principal, secundária e terciária. Esses dados foram organizados para as cidades da amostra, e a análise será realizada na próxima seção.

\subsection{Atividades produtivas dos municípios}

A partir do VAB é possível analisar quais são os setores produtivos mais importantes para cada município. Para os municípios analisados, foram abordados os principais setores, divididos em cinco categorias: 1. Agricultura, 2. Administração Pública, 3. Pecuária, 4. Florestal e 5. Serviços. Essas cinco categorias representam todas as principais atividades avaliadas entre 2010 e 2015.

Figura 9 - Atividade Produtiva Principal dos Municípios

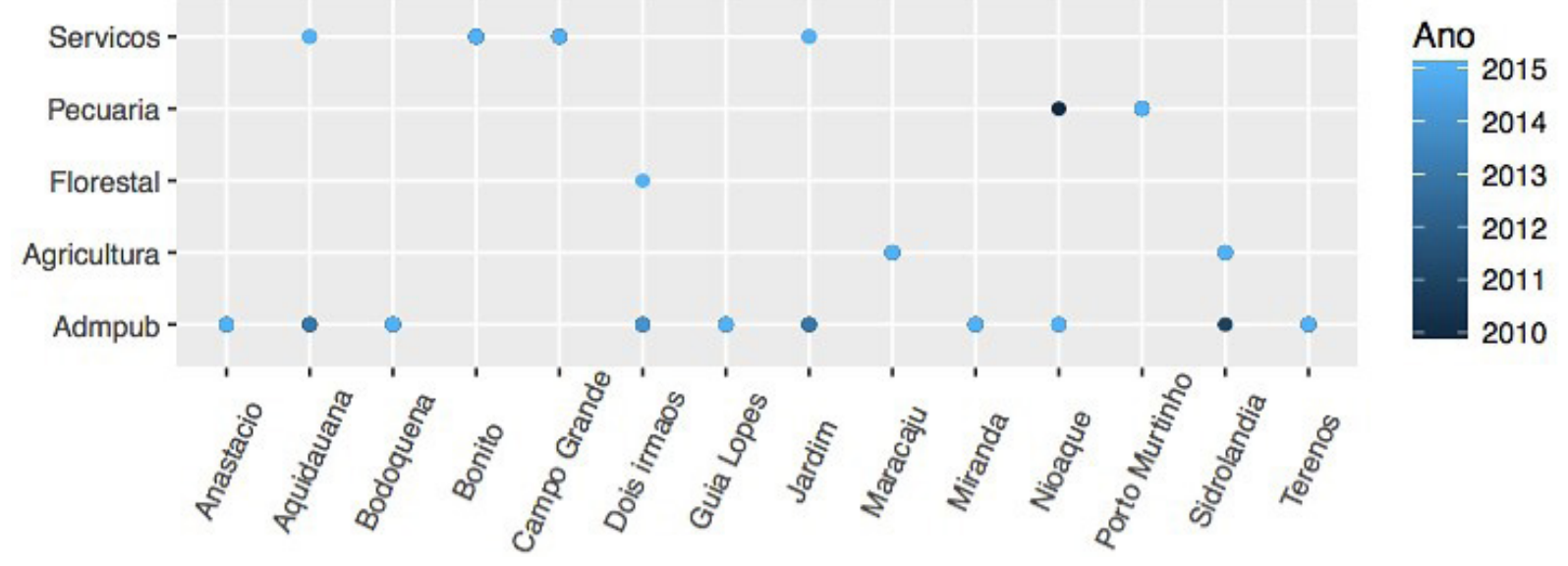

Fonte: IBGE (2017).

De acordo com dados do IBGE (2017), organizados na Figura 9, os municípios de Aquidauana, Bonito, Campo Grande e Jardim, em 2015, apresentaram uma economia baseada em serviços. Maracaju e Sidrolândia tinham economia lastreada na agricultura, Porto Murtinho na pecuária, enquanto que Dois Irmãos do Buriti apresentava base econômica na atividade florestal. Os demais municípios apresentaram suas atividades produtivas essencialmente ligadas à administração pública, dependente de salários e serviços estatais.

Os dados do IBGE (2017) ainda destacam que a atividade produtiva secundária dos municípios começa a se diversificar, ampliando a participação do serviço e agronegócio (pecuária e agricultura).

$\mathrm{Na}$ terceira atividade produtiva há diversificação ainda maior, entrando a economia do comércio, do setor florestal e predominantemente dos serviços. O município de Porto Murtinho, por exemplo, tem na sua atividade produtiva principal a pecuária, em segundo a administração pública e os serviços como terceira atividade. 
Com o objetivo de analisar as semelhanças entre os municípios analisados, foi aplicado a análise de cluster, que a literatura especializada denomina classificação não supervisionada, onde objetos em diferentes grupos são classificados. Essa classificação é realizada pelas atividades econômicas e, dessas atividades econômicas de cada município, a análise agrupa municípios semelhantes segundo a função de distância do "K-Means".

\section{ANÁLISE DE CLUSTER}

O método de agrupamento permite analisar dados em formato de matriz, e, para a presente análise de cluster, foi utilizada a técnica de similaridade mútua, na qual o programa estatístico " $R$ " agrupa observações que tenham uma similaridade comum com outras observações. Ao processo de mapeamento dos grupos similares é possível aplicar várias possibilidades e técnicas e, no caso desta pesquisa, a técnica utilizada para construir os clusters foi a do "K-Means", que permite relacionar as variáveis similares e resultados de cada município, indicando quais são mais próximos em sua economia, atividade produtiva e característica de desenvolvimento. Metodologicamente, a função distância do "K-Means" aplicada foi:

$$
J(C)=\sum_{\kappa=1}^{\kappa} \sum_{\chi_{i} \in C_{\kappa}}\left\|\chi_{i}-\mu_{\kappa}\right\|^{2}
$$

Aplicando o "K-Means" aos dados desta pesquisa, foram encontrados três clusters do conjunto de municípios analisados, apresentando alta similitude para a maioria dos municípios analisados. Campo Grande, nesse sentido, encontra-se isolada dos demais clusters, mostrando que não há similaridade entre a capital e os demais municípios - isso em função do tamanho da sua economia, da sua atividade principal e da sua dinâmica produtiva. Sidrolândia e Maracaju formaram um cluster único, e o cluster maior é formado pelos demais municípios que apresentam alta similaridade, conforme Figura 10.

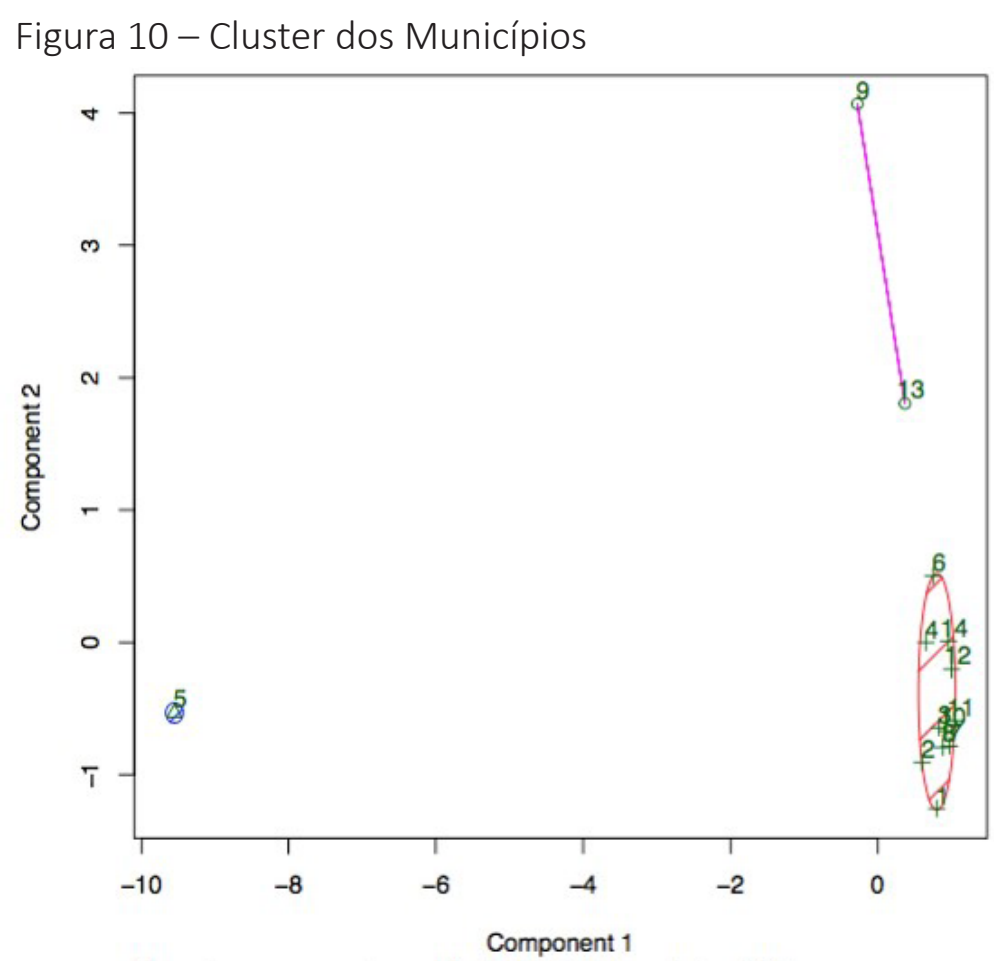

Fonte: IBGE (2017). 
Os números na Figura 10 são: 5 - município de Campo Grande, 9 e 13 - municípios de Sidrolândia e Maracaju e os demais números caracterizam os outros municípios da amostra, sendo que dois componentes aplicados na análise corroboram $90 \%$ da similaridade. Essa similaridade deve ser ponto de convergência para se formarem redes municipais capazes de desenvolver estruturas e sistemas produtivos próprios que fortaleçam cada município e esse cluster.

\section{ANÁLISE DE CORRELAÇÃO}

A matriz de correlação destaca as variáveis mais correlacionadas em uma tabela de dados. Nesta matriz da Figura 11, os coeficientes de correlação são coloridos de acordo com o valor. A matriz de correlação apresenta a significância entre as variáveis e resulta no caminho par a par que cada variável contribui para a associação com as demais.

Figura 11 - "Correlograma"

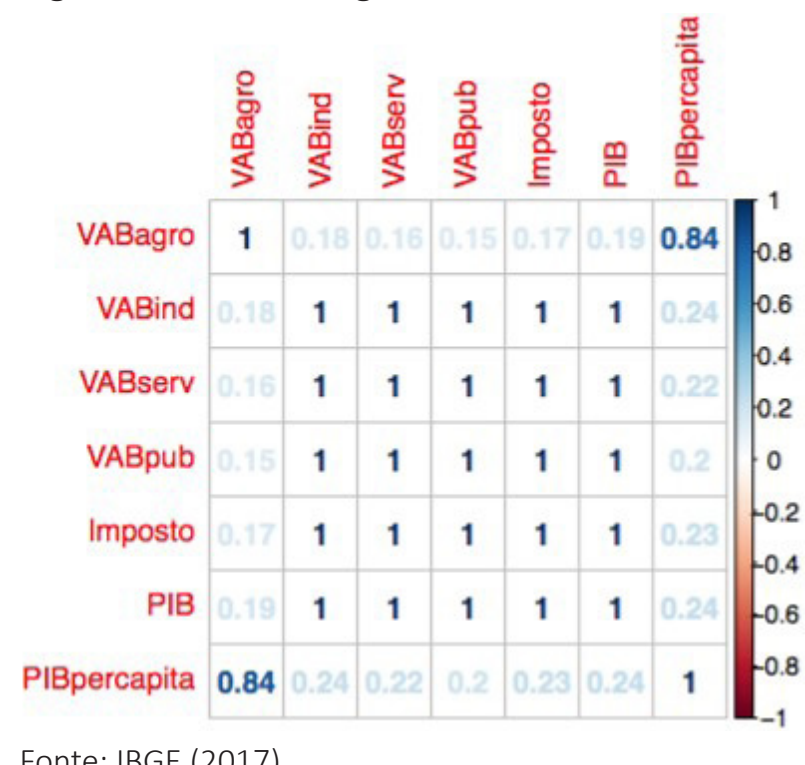

Fonte: IBGE (2017).

O desenvolvimento econômico medido pelo PIB tem uma alta correlação com o VAB da indústria, dos serviços e dos recursos públicos. Por outro lado, o PIB per capita está mais correlacionado com o VAB do agronegócio, que aumenta a renda população nos seus municípios dedicados aos serviços e produtividade da cadeia do agronegócio. As demais correlações apresentam sinal positivo, permitindo inferir que a caracterização destes municípios depende da dinâmica produtiva para sustentar o desenvolvimento econômico.

\section{ANÁLISE DAS EXPORTAÇÕES}

O Mato Grosso do Sul tem uma economia baseada na cadeia agroindustrial. Dentre as suas atividades produtivas principais estão as exportações de commodities e, especialmente, carne in natura. Com o intuito de conhecer as relações comerciais entre os países do Corredor Bioceânico, foi realizada, abaixo (Figura 12), uma análise das exportações entre países selecionados e o Mato Grosso do Sul. 
Figura 12 - Exportações entre Países Selecionados e o MS

\begin{tabular}{|c|c|c|c|c|c|c|c|c|c|c|}
\hline \multirow[b]{2}{*}{ Países } & \multicolumn{2}{|c|}{2015} & \multicolumn{2}{|c|}{2016} & \multicolumn{2}{|c|}{2017} & \multicolumn{2}{|c|}{2017 (jan-mar) } & \multicolumn{2}{|c|}{2018 (jan-mar) } \\
\hline & Valor & $\begin{array}{l}\text { Part. } \% \\
\text { no total }\end{array}$ & Valor & $\begin{array}{l}\text { Part.\% } \\
\text { no total }\end{array}$ & Valor & $\begin{array}{l}\text { Part.\% } \\
\text { no total }\end{array}$ & Valor & $\begin{array}{l}\text { Part.\% } \\
\text { no total }\end{array}$ & Valor & $\begin{array}{l}\text { Part.\% } \\
\text { no total }\end{array}$ \\
\hline Argentina & 211 & $4,5 \%$ & 165 & $4,1 \%$ & 247 & $5,2 \%$ & 60 & $5,4 \%$ & 59 & $5,0 \%$ \\
\hline Bolívia & 34 & $0,7 \%$ & 30 & $0,7 \%$ & 20 & $0,4 \%$ & 5 & $0,5 \%$ & 4 & $0,3 \%$ \\
\hline Chile & 67 & $1,4 \%$ & 105 & $2,6 \%$ & 93 & $1,9 \%$ & 20 & $1,7 \%$ & 33 & $2,7 \%$ \\
\hline China & 1.667 & $35,2 \%$ & 1.430 & $35,1 \%$ & 1.675 & $35,0 \%$ & 477 & $42,4 \%$ & 493 & $41,2 \%$ \\
\hline Paraguai & 36 & $0,8 \%$ & 34 & $0,8 \%$ & 25 & $0,5 \%$ & 6 & $0,5 \%$ & 6 & $0,5 \%$ \\
\hline Subtotal & 2.016 & $42,6 \%$ & 1.765 & $43,3 \%$ & 2.060 & $43,0 \%$ & 567 & $50,5 \%$ & 595 & $49,8 \%$ \\
\hline Outros & 2.720 & $57,4 \%$ & 2.307 & $56,7 \%$ & 2.726 & $57,0 \%$ & 556 & $49,5 \%$ & 601 & $50,2 \%$ \\
\hline Total & 4.735 & $100,0 \%$ & 4.071 & $100,0 \%$ & 4.785 & $100,0 \%$ & 1.123 & $100,0 \%$ & 1.196 & $100,0 \%$ \\
\hline
\end{tabular}

Fonte: BRASIL (2018).

As exportações do Mato Grosso do Sul para os países do Corredor e para a China são demonstradas na Figura 12, que apresenta 50\% das exportações entre Argentina (5\%), Chile (2,7\%), Paraguai (0,5\%) e China (41,2\%). Os dados apresentam evidências da importância do Corredor Bioceânico para o crescimento das relações produtivas entre os países e o efeito multiplicador do processo de desenvolvimento. Além disso, estudos ainda não disponíveis estimam que, em uma análise comparativa de mesmo modal, seria possível diminuir em 10\% o custo do transporte entre Mato Grosso do Sul e a China, maior parceiro comercial do Estado e do Brasil.

\section{CONSIDERAÇÕES FINAIS}

Os dados analisados propiciaram a análise exploratória das características dos municípios sul-mato-grossenses que compõem o Corredor Bioceânico, entre 2010 e 2015. As evidências empíricas demonstram diferenças de crescimento econômico ao longo dos anos e mudanças na dinâmica produtiva dos municípios. A variação econômica foi sempre positiva, com destaques para municípios empreendedores como Maracaju, Sidrolândia, Bonito e Dois Irmãos do Buriti, os quais se destacaram, especialmente, com relação ao PIB per capita, indicador que costuma resultar em desenvolvimento econômico, social e ambiental.

Comparado aos demais municípios que fazem parte do Corredor Bioceânico, Porto Murtinho é o município mais vulnerável do ponto de vista econômico e social, com baixa dinâmica produtiva, além de uma economia baseada na pecuária e em recursos da administração pública, apesar do crescimento do setor de turismo.

A partir da criação do Corredor Bioceânico, a dinâmica do escoamento da produção, as exportações, e o turismo podem mudar, potencializando desenvolvimento do Estado do Mato Grosso do Sul e do Brasil, porém são necessárias ações da iniciativa privada e de órgãos públicos para maximizar a possibilidade de resultados positivos. 


\section{REFERÊNCIAS}

BRASIL. Ministério do Desenvolvimento, Indústria e Comércio Exterior. Balança Comercial: unidades da federação. Brasília, [s.d.]. Disponível em: http://www.mdic.gov.br/comercio-exterior/estatisticas-decomercio-exterior/balanca-comercial-brasileira-unidades-da-federacao. Acesso em: abr. 2018.

CONSTANTINO, M.; PEGORARE, A. B.; COSTA, R. B. . Desempenho regional do IDH e do PIB per capita dos municípios de Mato Grosso do Sul, Brasil, entre 2000 e 2010. Interações, Campo Grande, v. 17, N. 2p. 234-46, abr./jun. 2016.

INSTITUTO BRASILEIRO DE GEOGRAFIA E ESTATÍSTICA (IBGE). Brasília, 2017. Disponível em: www.ibge. gov.br/sidra. Acesso em: abril de 2017.

MANKIW, N G. Introdução à economia. 3. ed .Tradução Norte-Americana. São Paulo: Thomson Pioneira, 2004.

PEGORARE, A. B. ; MORAES, P. M. ; MENDES, D. R. F. ; OlIVEIRA, M. A. C. ; COSTA, R. B. ; MOREIRA, T. B. S.; CUNHA, G. H. M. Spatial econometric analysis of the main agricultural commodities produced in CentralWest Region, Brazil. African Journal of Agricultural Research, v. 13, p. 167-80, 2018.

\section{Sobre os autores:}

Michel Constantino - Doutor em Economia pela Universidade de Brasília. Vice-Coordenador do Programa de Pós-Graduação em Desenvolvimento Local da Universidade Católica Dom Bosco - Mestrado e Doutorado, Campo Grande, MS. E-mail: michelangelo111@gmail.com, Orcid: http://orcid.org/0000-0003-2570-0209

Arlinda Cantero Dorsa - Doutora em Língua Portuguesa pela Pontifícia Universidade Católica (PUC/SP). Coordenadora e Docente do Programa de Mestrado e Doutorado em Desenvolvimento Local da UCDB, MS. E-mail: acdorsa@ucdb.br, Orcid: http://orcid.org/0000-0003-0957-9779

Daniel Silva Boson - Doutor em Direito pelo UniCEUB. Mestre em Direito pela Universidade Católica de Brasília. Especialista em Administração de Empresas, e em Defesa da Concorrência, pela Fundação Getúlio VArgas (FGV). Gestor Público Federal (EPPGG) prestando assessoria jurídico-econômica no Conselho Administrativo de Defesa Econômica (CADE). Professor de Economia e de Direito Econômico no UniCEUB. E-mail: danielboson@gmail.com, Orcid: http://orcid.org/0000-0001-5820-272X

Dany Rafael Fonseca Mendes - Mestre em Análise Econômica do Direito pela Universidade Católica de Brasília (UCB). Bacharél em Direito pela Universidade Federal de Ouro Preto (UFOP). Consultor (OAB/DF 36620). Professor Adjunto do UniCEUB e Pesquisador (ResearchGate Score 10.56), com participação em vários grupos/projetos de pesquisa e atuação em diversos periódicos. E-mail: rafael.dany@gmail.com, Orcid: http://orcid.org/0000-0002-2504-3272 